\title{
Nickel(II)-Catalyzed Synthesis of Sulfinates from Aryl and Heteroaryl Boronic Acids and the Sulfur Dioxide Surrogate DABSO
}

\author{
Pui Kin Tony Lo, Yiding Chen, and Michael C. Willis*i] \\ Department of Chemistry, Chemistry Research Laboratory, University of Oxford, Mansfield Road, Oxford OX1 3TA, United \\ Kingdom
}

\section{Supporting Information}

ABSTRACT: We report a redox-neutral $\mathrm{Ni}(\mathrm{II})$-catalyzed sulfination of readily available aryl and heteroaryl boronic acids. Using the combination of commercially available, airstable $\mathrm{NiBr}_{2} \cdot$ (glyme), a commercially available phenanthroline ligand, and DABSO, boronic acids are efficiently converted to the corresponding sulfinate salts, which can be further elaborated to valuable sulfonyl-containing groups, including sulfones, sulfonamides, sulfonyl fluorides, and sulfonate esters.

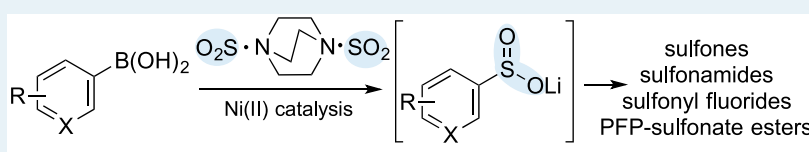

- redox neutral process

- inexpensive and abundant metal $(\sim £ 1 / \mathrm{mol})$

- catalyst loading down to $2.5 \mathrm{~mol} \%$

- broad scope of aryl and heteroaryl boronic acids

The catalyst loading can be reduced to $2.5 \mathrm{~mol} \%$ on a gram scale. This practically simple protocol tolerates an unprecedented range of pharmaceutically relevant and electron-poor (hetero)aryl boronic acids, allowing the direct synthesis of active pharmaceutical ingredients.

KEYWORDS: nickel, catalysis, sulfinates, boronic acids, sulfones, sulfonamides, sulfonyl fluorides, sulfur dioxide

S ulfonyl-containing $\left(-\mathrm{SO}_{2}-\right)$ compounds such as sulfones and sulfonamides have broad applications in fields ranging from synthetic chemistry, ${ }^{1}$ pharmaceuticals, and agrochemicals, to materials science (see Figures $1 \mathrm{a}-\mathrm{c}$ ). ${ }^{2}$ Conventional approaches to synthesize these valuable functional groups can often require multistep sequences. For example, sulfones are usually synthesized by oxidation of the corresponding sulfides, which, in turn, are commonly prepared from alkylation of thiols. ${ }^{3}$ The use of thiols is a limitation because of their often unpleasant odor, and their relatively limited availability from commercial vendors. Aryl sulfonamides, meanwhile, are most usually available from the combination of sulfonyl chlorides and amines. ${ }^{4}$ However, the preparation of the former via the electrophilic aromatic substitution $\left(\mathrm{S}_{\mathrm{E}} \mathrm{Ar}\right)$ of arenes requires harsh acidic reaction conditions, which limits functional group tolerance. ${ }^{5}$ In addition, the high levels of regiocontrol often observed in $S_{\mathrm{E}} \mathrm{Ar}$ processes makes access to all isomers of these products challenging.

Catalytic methods for the sulfination of abundant feedstocks, such as aryl halides and boronic acids, have had a tremdous impact of the synthesis of sulfonyl-containing molecules. ${ }^{6}$ In 2010 , our laboratory reported the use of $\mathrm{DABCO} \cdot\left(\mathrm{SO}_{2}\right)_{2}$ (DABSO) as a convenient sulfur dioxide surrogate. ${ }^{7}$ This airstable, easy-to-handle, and now commercially available solid has been employed by us, ${ }^{8}$ and others, ${ }^{9}$ to access a wide range of sulfonyl-containing products using metal catalysis. Inorganic sulfur dioxide surrogates such as $\mathrm{K}_{2} \mathrm{~S}_{2} \mathrm{O}_{5}$ and $\mathrm{Na}_{2} \mathrm{~S}_{2} \mathrm{O}_{5}$ have also been used, ${ }^{10}$ as have noncatalytic methods. ${ }^{11}$

The direct palladium-catalyzed synthesis of sulfinate salts from aryl halides represented a signficant advance, ${ }^{8 a, 12}$ as these versatile intermediates could be readily transformed to a variety of valuable functional group, such as sulfones, ${ }^{13}$ sulfonamides, ${ }^{8,14}$ sulfonyl fluorides, ${ }^{8 e, 15}$ and sulfonate esters. ${ }^{8 f}$ Sulfinates can also be employed as reaction partners in desulfinylative cross-coupling processes, ${ }^{16}$ and as radical precursors. ${ }^{17}$ Later, aryl boronic acids were also employed in place of aryl halides, and these substrates have also been used in combination with $\mathrm{Au}(\mathrm{I}),{ }^{18} \mathrm{Pd}(\mathrm{II}),{ }^{8 \mathrm{c}, 10 \mathrm{~b}, 19}$ and $\mathrm{Cu}(\mathrm{I})^{8 \mathrm{~d}}$ catalysts (see Figure 1d). Despite these advances in sulfinate synthesis, signficant challenges remain unsolved. For example, the scope of these processes is generally limited to electronrich or neutral aryl systems. Electron-poor aryl and heteroaryl boronic acids commonly provide only low yields of products, or fail completely. ${ }^{8 c, d, f, g, 18-20}$ An exception to this is the palladium-catalyzed system reported by $\mathrm{Chen}$ and $\mathrm{Tu}$, in which a bespoke $N$-heterocyclic carbene ligand enables some success with these substrates for the synthesis of simple sulfone products. However, a general catalytic system that employs commerical reaction components and is able to tolerate a broad range of electronically varied boronic acids is as yet unknown.

In recent years, a focus of both academic and industrial communities has been the use of abundant base-metal catalysts in synthetic chemistry. In particular, the replacement of precious metal catalysts with these lower-cost, more-sustainable metals that are less susceptible to risk of supply, has attracted significant attention. ${ }^{21}$ Nickel catalysis features prominently in this field, not only because of its significantly lower cost, relative to palladium, but also because it frequently provides alternative, often complementary, reactivity. ${ }^{22}$ For

Received: October 9, 2019

Revised: October 22, 2019 
a) Sulfones in organic synthesis: The Julia-Kocienski olefination<smiles>[R]C=C[R]</smiles>

b) Sulfonyl-derivatives as pharmaceuticals and agrochemicals

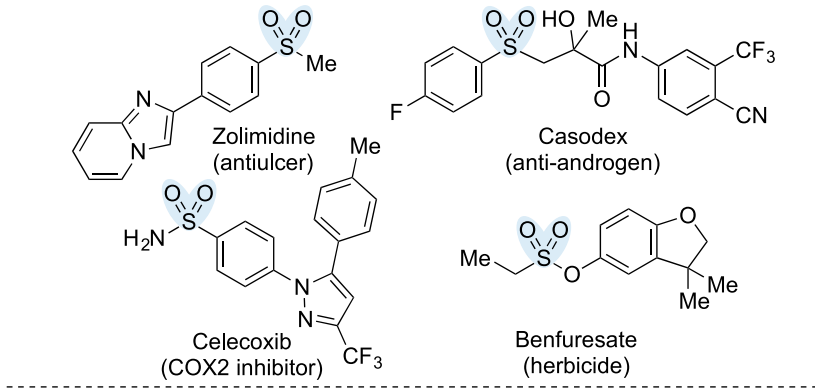

c) Sulfone-containing materials

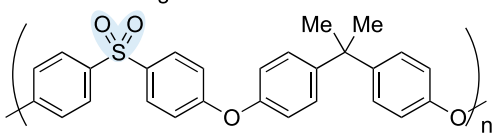

polysulfone (PSF, themoplastic)

d) Sulfinate synthesis from boronic acids

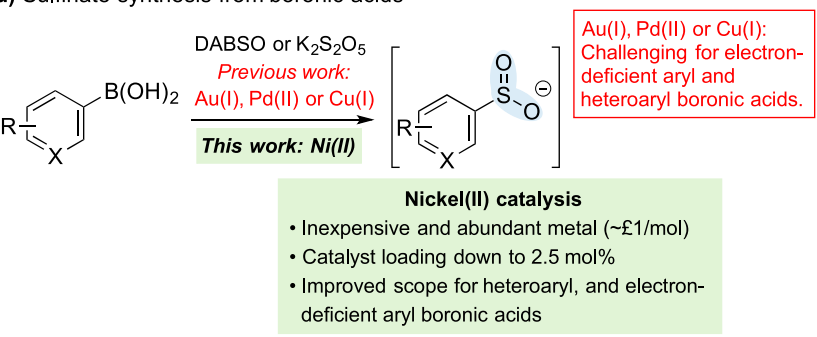

Figure 1. $(a-c)$ Applications of sulfones and sulfonamides; and (d) catalytic synthesis of sulfinates from boronic acids.

example, nickel undergoes ready oxidative addition with lessreactive and more-abundant electrophiles such as aryl chlorides, ethers, and carbamates. $^{22 a-c}$ In addition, it can be used, in combination with photoredox catalysts, to deliver modes of reactivity ${ }^{23}$ that are challenging to achieve with palladium systems. Given these advantages, we speculated that nickel catalysis could deliver new reactivities in sulfination chemistry and address the limitations of earlier catalytic methods (see Figure 1d).

We selected the addition of phenylboronic acid to DABSO as a test platform and evaluated a range of $\mathrm{Ni}$ (II) catalysts (see Table 1). We were pleased to find that using $10 \mathrm{~mol} \%$ of commercially available and air-stable $\mathrm{NiBr}_{2} \cdot$ (glyme), in combination with $10 \mathrm{~mol} \%$ of 3,4,7,8-tetramethyl-1,10phenanthroline (tmphen) as ligand, was sufficient to promote the reaction, providing the targeted sulfinate in $91 \%$ yield. The reaction used DMI as a solvent at $100{ }^{\circ} \mathrm{C}$ and required only 0.6 equiv of DABSO and 1 equiv of $\mathrm{LiOt}$-Bu (Table 1 , entry 1 ). A lower reaction temperature $\left(90{ }^{\circ} \mathrm{C}\right)$, higher loading of ligand, or base, or increasing the concentration, all provided lessefficient reactions (Table 1 , entries 2-6). We also found that using a strong base was crucial in this transformation, with $\mathrm{LiO} t$-Bu being optimal; using a weaker base or $\mathrm{KO} t-\mathrm{Bu}$ resulted in diminished yields (Table 1, entries 7 and 8). Substituting DABSO for an inorganic source of sulfur dioxide $\left(\mathrm{K}_{2} \mathrm{~S}_{2} \mathrm{O}_{5}\right)$, or replacing phenylboronic acid with potassium phenyltrifluoroborate was unproductive (Table 1, entries 9 and 10). Full details of the reaction optimization are provided in the Supporting Information.
Table 1. Optimization of Reaction Conditions for the Formation of Sulfinate 1a from Phenylboronic Acid ${ }^{a}$

\begin{tabular}{|c|c|c|}
\hline & $\begin{array}{c}\mathrm{NiBr}_{2} \cdot(\text { glyme })(10 \mathrm{~mol} \%) \\
\text { tmphen }(10 \mathrm{~mol} \%) \\
\text { DABSO ( } 0.6 \text { equiv.) } \\
\end{array}$ & $\overbrace{\text { SLi }}^{\text {OI }}$ \\
\hline & $\begin{array}{l}\text { LiOt-Bu (1 equiv.) } \\
\text { DMI, } 100^{\circ} \mathrm{C}, 16 \mathrm{~h}\end{array}$ & $1 \mathrm{a}$ \\
\hline Entry & Variation & Yield of $1 \mathrm{a}(\%)$ \\
\hline 1 & as above & 91 \\
\hline 2 & $90^{\circ} \mathrm{C}$ & 31 \\
\hline 3 & $20 \mathrm{~mol} \%$ ligand & 28 \\
\hline 4 & 1.0 equiv. DABSO & 90 \\
\hline 5 & 2.0 equiv. $\mathrm{LiO} t-\mathrm{Bu}$ & 68 \\
\hline 6 & 0.4 M DMI & 78 \\
\hline 7 & $0.4 \mathrm{M} \mathrm{DMI}, \mathrm{Li}_{2} \mathrm{CO}_{3}$ instead of $\mathrm{LiOt}-\mathrm{Bu}$ & 33 \\
\hline 8 & $0.4 \mathrm{M} \mathrm{DMI}, \mathrm{KO} t-\mathrm{Bu}$ instead of $\mathrm{LiO} t-\mathrm{Bu}$ & 64 \\
\hline 9 & 1.0 equiv. $\mathrm{K}_{2} \mathrm{~S}_{2} \mathrm{O}_{5}$ instead of DABSO & 0 \\
\hline 10 & $\mathrm{PhBF}_{3} \mathrm{~K}$ instead of phenylboronic acid & 0 \\
\hline & DABSO & $\int_{\mathrm{Me}}^{\mathrm{Me}}$ \\
\hline
\end{tabular}

${ }^{a}$ Reaction conditions: phenylboronic acid ( $0.2 \mathrm{mmol}, 1.0$ equiv), $\mathrm{NiBr}_{2} \cdot$ (glyme) (10 mol \%), tmphen (10 mol \%), DABSO (0.12 mmol, 0.6 equiv), $\mathrm{LiO} t$-Bu (0.2 mmol, 1.0 equiv), DMI $(1.0 \mathrm{~mL}, 0.2 \mathrm{M})$. Yields were calculated from HPLC analysis using acetophenone as an internal standard.

With the optimized conditions in hand, we examined the scope, with respect to boronic acids, by reacting the in situ formed sulfinates with tert-butyl bromoacetate as the electrophile, to prepare the corresponding sulfones in a one-pot twostep sequence (see Table 2). Generally, a wide range of aryl boronic acids could be effectively converted to sulfinates and then to sulfones. Boronic acids bearing different electronic substitutions were well-tolerated, with electronically neutral phenyl (2a) and p-trimethylsilyl (2b), and electron-rich $p$ methoxy (2c) and p-thiomethyl (2d) substituents delivering excellent isolated yields. Previously challenging substrates with electron-withdrawing groups could also be incorporated in the arene unit, including sensitive functional groups such as nitrile $(\mathbf{2 g})$, ketone $(\mathbf{2} \mathbf{i})$, and ester $(\mathbf{2} \mathbf{j})$, as well as the first example of a trifluoromethylated aryl boronic acid being used in catalytic sulfination chemistry (2f). Boronic acids substituted with all four halogens $(\mathbf{2 k - 2 0})$ were well-tolerated under the reaction conditions, with the caveat that using $\mathrm{NiI}_{2}$ as the catalyst was necessary when $p$-iodophenyl boronic acid (2o) was the substrate. For this example, using the original $\mathrm{NiBr}_{2} \cdot$ (glyme) catalyst resulted in a degree of bromo/iodo substitution in the product. The catalyst loading could be lowered to $2.5 \mathrm{~mol} \%$, delivering $70 \%$ isolated yield of sulfone $(2 \mathrm{~m})$ on a $0.2 \mathrm{mmol}$ scale, and a $71 \%$ yield when performed on a gram scale (7 $\mathrm{mmol})$ at a slightly elevated temperature $\left(110^{\circ} \mathrm{C}\right)$. Further reducing the catalyst loading to $1 \mathrm{~mol} \%$ resulted in diminished yields. Methylthio (2d)- and methanesulfonyl (2h)-substituted examples showcase the potential utility of this reaction, demonstrating how it is possible to access mixed-oxidationstate S-centers, as well as disparate sulfonyl functional groups.

Meta-substituted boronic acids were also reacted well, giving identical yields compared to the para-substituted counterpart ( $2 \mathrm{~g}$ and $\mathbf{2 q}$ ). However, ortho-substituted (2r) and alkenyl boronic acid (2s) were less successful, with only poor to modest product yields isolated even at elevated temperature. 
Table 2. Scope of the Boronic Acid Reaction Component ${ }^{a}$

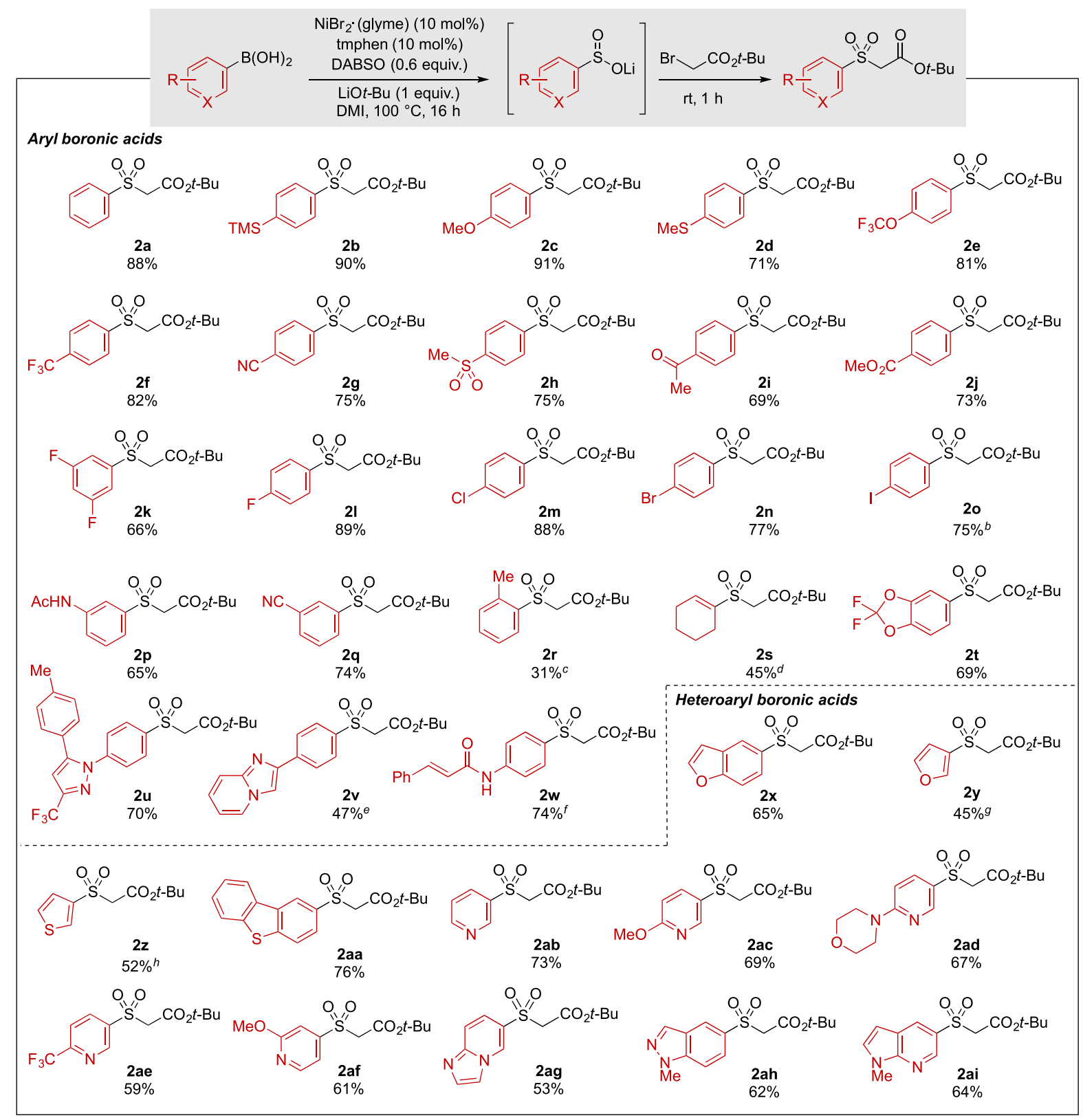

${ }^{a}$ Reaction conditions: (hetero)aryl boronic acid ( $0.2 \mathrm{mmol}, 1.0$ equiv), $\mathrm{NiBr}_{2} \cdot($ glyme $)(10 \mathrm{~mol} \%)$, tmphen (10 mol \%), DABSO (0.12 mmol, 0.6 equiv), $\mathrm{LiOt}$ - $\mathrm{Bu}\left(0.2 \mathrm{mmol}, 1.0\right.$ equiv), DMI $(1.0 \mathrm{~mL}, 0.2 \mathrm{M}), 100{ }^{\circ} \mathrm{C}, 16 \mathrm{~h}$, then tert-butyl bromoacetate $(2.0 \mathrm{equiv}), \mathrm{rt}, 1 \mathrm{~h} .{ }^{b} \mathrm{NiI} \mathrm{I}_{2}$ used as catalyst. ${ }^{c} 120{ }^{\circ} \mathrm{C} .{ }^{d} 110{ }^{\circ} \mathrm{C} .{ }^{e} 6 \mathrm{~h}$ for second step. ${ }^{f} \mathrm{~h}$ for second step. ${ }^{g} 1 \mathrm{~h}$ for first step. ${ }^{h} \mathrm{~h}$ for first step.

We were pleased to find that several pharmaceutically relevant boronic acids reacted smoothly under the optimized conditions, delivering the sulfonylarene core of the COX2 inhibitor Celecoxib (2u), antiulcer drug Zolimidine (2v) and CrtN inhibitor NP16 (2w). ${ }^{2 b}$ A range of heteroaryl boronic acids were also suitable substrates, including $O-(2 \mathbf{x}, 2 \mathbf{y})$ and $S$ heterocycles $(\mathbf{2 z}, \mathbf{2 a a})$, as well as a variety of challenging substituted pyridyl groups (2ab-2af). Imidazopyridine (2ag), indazole (2ah), and azaindole (2ai) groups were also included, delivering the desired sulfones in good yields. It is also worth noting that, in previous reported sulfinations of aryl boronic acids using $\mathrm{Au}(\mathrm{I}),{ }^{18} \mathrm{Pd}(\mathrm{II}),{ }^{8 \mathrm{c}, 19,20}$ or $\mathrm{Cu}(\mathrm{I})^{8 \mathrm{~d}}$ catalytic systems, electron-deficient aryl (e.g., nitrile, trifluoromethyl) and pyridine-derived boronic acids generally reacted poorly or failed completely. However, these substrates reacted smoothly under the $\mathrm{Ni}$ (II) catalytic systems reported here, highlighting the utility of the present chemistry.

We then explored alternative derivatization processes for the sulfinate intermediates. $p$-Chlorophenylboronic acid was selected as the model substrate. Table 3 a outlines the sulfones prepared by combining the sulfinates with a variety of carbonbased electrophiles, including alkyl halides (3a), heteroaryl halides (3b), diaryliodonium salts (3c), and epoxides. The antiulcer drug Zolimidine (3d) was prepared conveniently using methyl iodide as the alkylating agent. In situ alkylation of the sulfinate intermediates with allyl bromide afforded allyl sulfones $(\mathbf{3 e}-\mathbf{3 h})$, which are a class of sulfone with established utility in desulfinative cross-coupling and aromatic sulfonyla- 
Table 3. Scope of Carbon- and Nitrogen-Based Electrophiles To Form Sulfones and Sulfonamides ${ }^{a}$

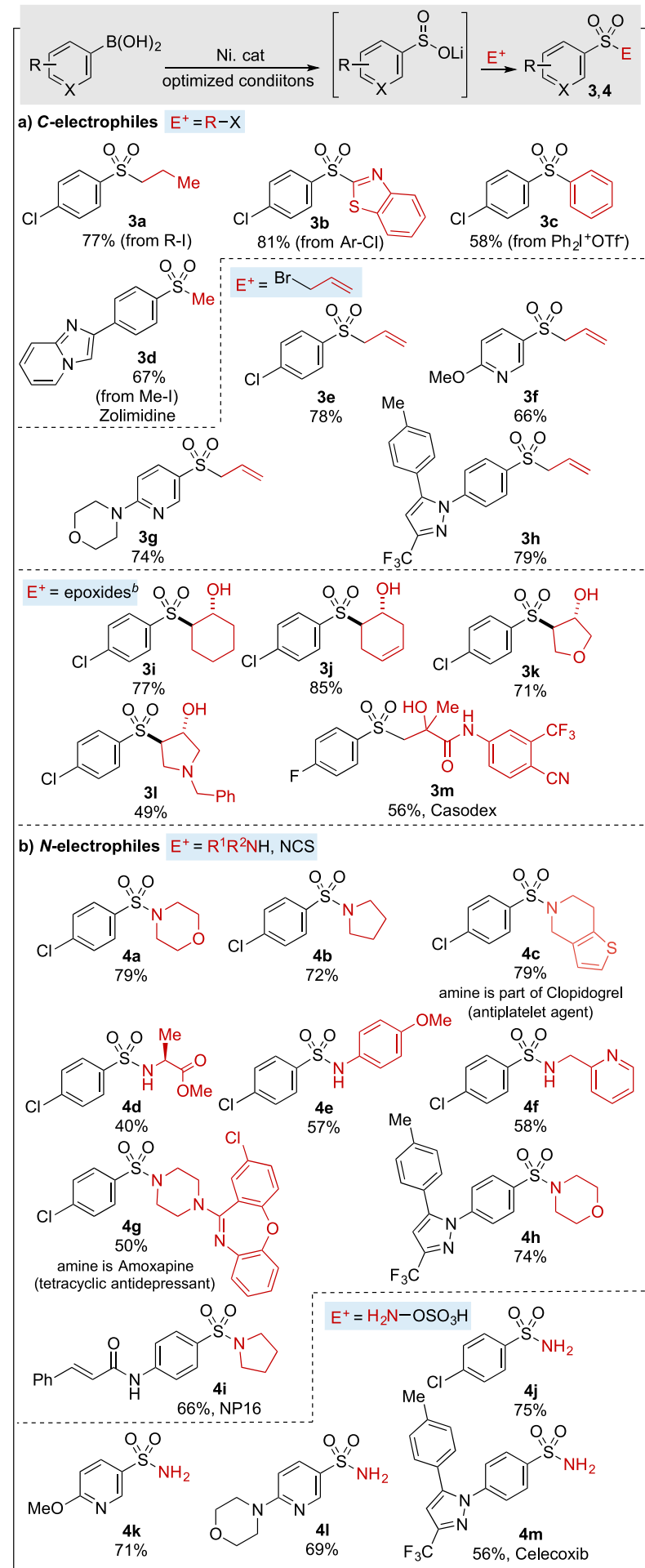

${ }^{a}$ Reaction conditions for sulfinate derivatization step: $\mathrm{E}^{+}$( 2 equiv), $\mathrm{rt}$ or $100{ }^{\circ} \mathrm{C}, 1 \mathrm{~h}$. For epoxides: aqueous workup, DIPEA (3 equiv), epoxide (5 equiv), $\mathrm{H}_{2} \mathrm{O}, 100{ }^{\circ} \mathrm{C}, 48$ h. For sulfonamides: $\mathrm{R}^{1} \mathrm{R}^{2} \mathrm{NH}$ (1.5 equiv), $\mathrm{NCS}$ ( 1.5 equiv), $0{ }^{\circ} \mathrm{C}$ to rt, $1 \mathrm{~h} ; \mathrm{H}_{2} \mathrm{~N}-\mathrm{OSO}_{3} \mathrm{H}$ (2 equiv), rt, $\mathrm{H}_{2} \mathrm{O}, 24 \mathrm{~h}$. For individual variations, see the Supporting Information. ${ }^{b}$ For products $3 \mathbf{i}-3 \mathbf{l}, \mathrm{dr}>20: 1$.

tion processes. ${ }^{16 \mathrm{~d}, 24}$ Notably, pyridine- (3f, 3g) and Celecoxibderived (3h) allyl sulfones were prepared in good yields. Epoxide ring opening delivered the corresponding $\beta$-hydroxy sulfones in good yields $(3 \mathbf{i}-\mathbf{3 m})$ and allowed the direct synthesis of the antiandrogen pharmaceutical Casodex $(3 \mathrm{~m})$. The examples in Table $3 \mathrm{~b}$ show that sulfonamides are accessible if $\mathrm{N}$-electrophiles are used. Secondary and tertiary sulfonamides are available using an electrophile generated from the combination of an appropriate amine and $\mathrm{N}$-chlorosuccinimide (NCS). ${ }^{14 \mathrm{~b}}$ The conditions can tolerate both secondary $(4 a-4 c)$ and primary (4f) amines, including amino acids (4d) and anilines (4e), as well as other biologically relevant amines (4c, 4g). Different boronic acid reaction partners were also employed, allowing the preparation of an analogue of Celecoxib (4h) and the CrtN inhibitor NP16 (4i). Primary sulfonamides were available by combining the in-situgenerated sulfinates with hydroxylamine- $O$-sulfonic acid $\left(\mathrm{H}_{2} \mathrm{NOSO}_{3} \mathrm{H}\right){ }^{25}$ Several pyridyl $(4 \mathbf{k}, 4 \mathbf{l})$ examples were prepared in good yield, as was the primary sulfonamide Celecoxib (4m).

Sulfonyl fluorides have recently received increased recognition in the field of chemical biology, because of their unconventional balance between reactivity and stability under physiological conditions. ${ }^{26}$ Table 4 shows that, by using $N$ fluorobenzenesulfonimide (NFSI) as the electrophilic component, we are able to prepare a selection of sulfonyl fluorides in good to modest yields.

Table 4. Preparation of Sulfonyl Fluorides, Using NFSI as the Electrophilic Reagent ${ }^{a}$

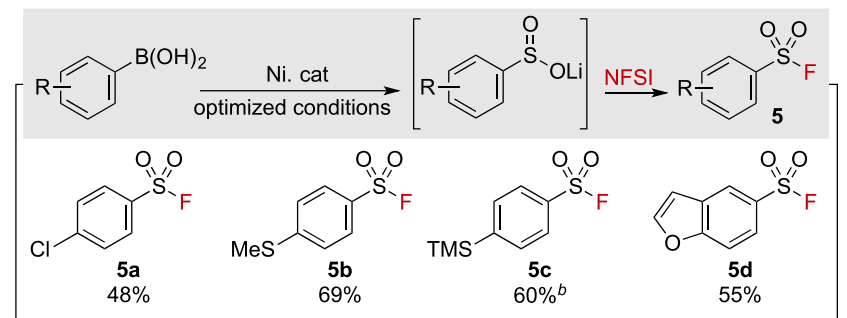

${ }^{a}$ Reaction conditions for sulfinate derivatization step: aqueous workup, then DIPEA ( 3 equiv), NFSI ( 1.5 equiv), rt, $1 \mathrm{~h} .{ }^{b}$ NFSI ( 1 equiv) used.

Pentafluorophenyl (PFP) sulfonate esters are often crystalline and bench-stable replacements for sulfonyl chlorides. ${ }^{8 f, 27}$ Our laboratory has recently reported the preparation of PFP sulfonate esters using copper-catalyzed oxidative coupling of sulfinates and pentafluorophenol. ${ }^{81}$ Here, we show that the copper-catalyzed PFP sulfonate ester synthesis can be combined with nickel-catalyzed sulfinate formation. Accordingly, PFP-ester 6 was prepared in 52\% yield from the corresponding boronic acid (see Scheme 1).

In conclusion, we have developed the first examples of nickel-catalyzed sulfination. The developed chemistry is redoxneutral and combines (hetero)aryl boronic acids and DABSO

Scheme 1. Synthesis of a PFP Sulfonate Ester

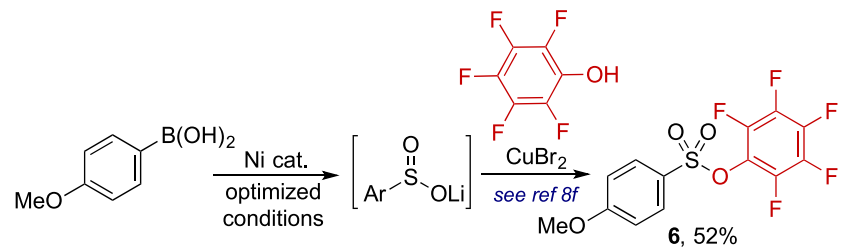


as the source of sulfur dioxide. A broad range of boronic acids was tolerated, including electron-deficient and heterocyclic, including pyridyl, systems. Significantly, these types of boronic acids delivered only low yields or failed completely with prior methods, which were based predominantly on precious-metal catalysts, and often required custom ligands. The developed protocol can be scaled up to a preparative gram scale using 2.5 mol \% catalyst. The in-situ-formed sulfinates were elaborated efficiently to sulfones, sulfonamides, sulfonyl fluoride, and PFP sulfonate esters. The procedure was applicable to the direct synthesis of several active pharmaceutical ingredients, providing a good demonstration of the functional group compatibility of the system. Given the increasing attention on nickel as a sustainable and inexpensive base-metal catalyst, and the importance of sulfonyl-containing compounds in both pharmaceuticals and agrochemicals, we anticipate wide uptake of the reported methods.

\section{ASSOCIATED CONTENT}

\section{S Supporting Information}

The Supporting Information is available free of charge on the ACS Publications website at DOI: 10.1021/acscatal.9b04363.

Experimental procedures and supporting characterization data and spectra (PDF)

\section{AUTHOR INFORMATION}

\section{Corresponding Author}

*E-mail: michael.willis@chem.ox.ac.uk.

\section{ORCID}

Michael C. Willis: 0000-0002-0636-6471

\section{Notes}

The authors declare no competing financial interest.

\section{ACKNOWLEDGMENTS}

We thank the EPSRC (EP/K024205/1) for support of this study.

\section{REFERENCES}

(1) (a) Julia, M.; Paris, J.-M. Syntheses a l'aide de Sulfones v(+)Methode de Synthese Generale de Doubles Liaisons. Tetrahedron Lett. 1973, 14, 4833-4836. (b) Blakemore, P. R.; Cole, W. J.; Kocieński, P. J.; Morley, A. A Stereoselective Synthesis of trans-1,2-Disubstituted Alkenes Based on the Condensation of Aldehydes with Metallated 1Phenyl-1H-tetrazol-5-yl Sulfones. Synlett 1998, 1998, 26-28.

(2) (a) Emmett, E. J.; Willis, M. C. The Development and Application of Sulfur Dioxide Surrogates in Synthetic Organic Chemistry. Asian J. Org. Chem. 2015, 4, 602-611. (b) Gao, P.; Davies, J.; Kao, R. Y. T. Dehydrosqualene Desaturase as a Novel Target for Anti-Virulence Therapy against Staphylococcus aureus. mBio 2017, 8, DOI: 10.1128/mBio.01224-17. (c) Taylor, R. J. K.; Casy, G. The Ramberg-Bäcklund Reaction. Org. React. 2003, 62, 359-475. (d) Söderman, S. C.; Schwan, A. L. 1,2-Dibromotetrachloroethane: An Ozone-Friendly Reagent for the in Situ Ramberg-Bäcklund Rearrangement and Its Use in the Formal Synthesis of E-Resveratrol. J. Org. Chem. 2012, 77, 10978-10984.

(3) (a) Kozak, J. A.; Dake, G. R. Total Synthesis of (+)-Fawcettidine. Angew. Chem., Int. Ed. 2008, 47, 4221-4223. (b) Jana, N. K.; Verkade, J. G. Phase-Vanishing Methodology for Efficient Bromination, Alkylation, Epoxidation, and Oxidation Reactions of Organic Substrates. Org. Lett. 2003, 5, 3787-3790. (c) Sato, K.; Hyodo, M.; Aoki, M.; Zheng, X.-Q.; Noyori, R. Oxidation of Sulfides to Sulfoxides and Sulfones with 30\% Hydrogen Peroxide Under Organic Solvent- and Halogen-Free Conditions. Tetrahedron 2001, 57, 2469-2476. (d) Trost, B. M.; Curran, D. P.
Chemoselective Oxidation of Sulfides to Sulfones with Potassium Hydrogen Persulfate. Tetrahedron Lett. 1981, 22, 1287-1290.

(4) Schmitt, A.-M. D.; Schmitt, D. C., Synthesis of Sulfonamides. In Synthetic Methods in Drug Discovery; Blakemore, D. C., Doyle, P. M., Fobian, Y. M., Eds.; Royal Society of Chemistry: Cambridge, 2016; Vol. 2, pp 123-138.

(5) Bassin, J. P.; Cremlyn, R. J.; Swinbourne, F. J. Review. Chlorosulfonation of Aromatic and Hetero-Aromatic Systems. Phosphorus, Sulfur Silicon Relat. Elem. 1991, 56, 245-275.

(6) (a) Zheng, D.; Wu, J. Sulfur Dioxide Insertion Reactions for Organic Synthesis; Springer: Berlin, 2017. (b) Willis, M. C. New Catalytic Reactions Using Sulfur Dioxide. Phosphorus, Sulfur Silicon Relat. Elem. 2019, 194, 654-657.

(7) (a) Nguyen, B.; Emmett, E. J.; Willis, M. C. Palladium-Catalyzed Aminosulfonylation of Aryl Halides. J. Am. Chem. Soc. 2010, 132, 16372-16373. (b) Woolven, H.; González-Rodríguez, C.; Marco, I.; Thompson, A. L.; Willis, M. C. DABCO-Bis(sulfur dioxide), DABSO, as a Convenient Source of Sulfur Dioxide for Organic Synthesis: Utility in Sulfonamide and Sulfamide Preparation. Org. Lett. 2011, 13, 4876-4878.

(8) (a) Emmett, E. J.; Hayter, B. R.; Willis, M. C. PalladiumCatalyzed Synthesis of Ammonium Sulfinates from Aryl Halides and a Sulfur Dioxide Surrogate: A Gas-and Reductant-Free Process. Angew. Chem., Int. Ed. 2014, 53, 10204-10208. (b) Flegeau, E. F.; Harrison, J.; Willis, M. C. One-Pot Sulfonamide Synthesis Exploiting the Palladium-Catalyzed Sulfination of Aryl Iodides. Synlett 2016, 27, 101-105. (c) Deeming, A. S.; Russell, C. J.; Willis, M. C. Palladium(II)-Catalyzed Synthesis of Sulfinates from Boronic Acids and DABSO: A Redox-Neutral, Phosphine-Free Transformation. Angew. Chem., Int. Ed. 2016, 55, 747-750. (d) Chen, Y.; Willis, M. C. Copper(I)-Catalyzed Sulfonylative Suzuki-Miyaura Cross-Coupling. Chem. Sci. 2017, 8, 3249-3253. (e) Davies, A. T.; Curto, J. M.; Bagley, S. W.; Willis, M. C. One-Pot Palladium-Catalyzed Synthesis of Sulfonyl Fluorides From Aryl Bromides. Chem. Sci. 2017, 8, 12331237. (f) Vedovato, V.; Talbot, E. P. A.; Willis, M. C. CopperCatalyzed Synthesis of Activated Sulfonate Esters from Boronic Acids, DABSO, and Pentafluorophenol. Org. Lett. 2018, 20, 5493-5496. (g) Chen, Y.; Murray, P. R. D.; Davies, A. T.; Willis, M. C. Direct Copper-Catalyzed Three-Component Synthesis of Sulfonamides. J. Am. Chem. Soc. 2018, 140, 8781-8787.

(9) (a) Zhu, H.; Shen, Y.; Deng, Q.; Huang, C.; Tu, T. One-Pot Bimetallic Pd/Cu-Catalyzed Synthesis of Sulfonamides from Boronic Acids, DABSO and O-Benzoyl Hydroxylamines. Chem. - Asian J. 2017, 12, 706-712. (b) Wang, X.; Xue, L.; Wang, Z. A CopperCatalyzed Three-Component Reaction of Triethoxysilanes, Sulfur Dioxide, and Hydrazines. Org. Lett. 2014, 16, 4056-4058. (c) Zheng, D.; Mao, R.; Li, Z.; Wu, J. A Copper(I)-Catalyzed Three-Component Reaction of Triethoxysilanes, Sulfur Dioxide, and Alkyl Halides. Org. Chem. Front. 2016, 3, 359-363. (d) Mao, R.; Zheng, D.; Xia, H.; Wu, J. Copper(I)-Catalyzed Sulfonylation of (2-Alkynylaryl)boronic Acids With DABSO. Org. Chem. Front. 2016, 3, 693-696. (e) Wang, K.; Wang, G.; Duan, G.; Xia, C. Cobalt(II)-Catalyzed Remote C5Selective C-H Sulfonylation of Quinolines via Insertion of Sulfur Dioxide. RSC Adv. 2017, 7, 51313-51317.

(10) (a) Ye, S.; Wu, J. A Palladium-Catalyzed Reaction of Aryl Halides, Potassium Metabisulfite, and Hydrazines. Chem. Commun. 2012, 48, 10037-10039. (b) Wang, M.; Zhao, J.; Jiang, X. Aryl Methyl Sulfone Construction from Eco-Friendly Inorganic Sulfur Dioxide and Methyl Reagents. ChemSusChem 2019, 12, 3064-3068. (c) Wang, M.; Fan, Q.; Jiang, X. Metal-Free Construction of Primary Sulfonamides Through Three Diverse Salts. Green Chem. 2018, 20, 5469-5473.

(11) (a) Zheng, D. Q.; An, Y. Y.; Li, Z. H.; Wu, J. Metal-Free Aminosulfonylation of Aryldiazonium Tetrafluoroborates with DABCO. $\left(\mathrm{SO}_{2}\right)_{2}$ and Hydrazines. Angew. Chem., Int. Ed. 2014, 53, 2451-2454. (b) Tsai, A. S.; Curto, J. M.; Rocke, B. N.; DechertSchmitt, A.-M. R.; Ingle, G. K.; Mascitti, V. One-Step Synthesis of Sulfonamides from N-Tosylhydrazones. Org. Lett. 2016, 18, 508-511. (c) Deeming, A. S.; Russell, C. J.; Willis, M. C. Combining 
Organometallic Reagents, the Sulfur Dioxide Surrogate DABSO, and Amines: A One-Pot Preparation of Sulfonamides, Amenable to Array Synthesis. Angew. Chem., Int. Ed. 2015, 54, 1168-1171.

(12) Shavnya, A.; Coffey, S. B.; Smith, A. C.; Mascitti, V. PalladiumCatalyzed Sulfination of Aryl and Heteroaryl Halides: Direct Access to Sulfones and Sulfonamides. Org. Lett. 2013, 15, 6226-6229.

(13) (a) Deeming, A. S.; Russell, C. J.; Hennessy, A. J.; Willis, M. C. DABSO-Based, Three-Component, One-Pot Sulfone Synthesis. Org. Lett. 2014, 16, 150-153. (b) Rocke, B. N.; Bahnck, K. B.; Herr, M.; Lavergne, S.; Mascitti, V.; Perreault, C.; Polivkova, J.; Shavnya, A. Synthesis of Sulfones from Organozinc Reagents, DABSO, and Alkyl Halides. Org. Lett. 2014, 16, 154-157.

(14) (a) Pandya, R.; Murashima, T.; Tedeschi, L.; Barrett, A. G. M. Facile One-Pot Synthesis of Aromatic and Heteroaromatic Sulfonamides. J. Org. Chem. 2003, 68, 8274-8276. (b) Shavnya, A.; Hesp, K. D.; Tsai, A. S. A Versatile Reagent and Method for Direct Aliphatic Sulfonylation. Adv. Synth. Catal. 2018, 360, 1768-1774.

(15) Tribby, A. L.; Rodriguez, I.; Shariffudin, S.; Ball, N. D. PdCatalyzed Conversion of Aryl Iodides to Sulfonyl Fluorides Using $\mathrm{SO}_{2}$ Surrogate DABSO and Selectfluor. J. Org. Chem. 2017, 82, 22942299.

(16) (a) Ortgies, D. H.; Hassanpour, A.; Chen, F.; Woo, S.; Forgione, P. Desulfination as an Emerging Strategy in PalladiumCatalyzed C-C Coupling Reactions. Eur. J. Org. Chem. 2016, 2016, 408-425. (b) Markovic, T.; Rocke, B. N.; Blakemore, D. C.; Mascitti, V.; Willis, M. C. Pyridine Sulfinates as General Nucleophilic Coupling Partners in Palladium-Catalyzed Cross-Coupling Reactions with Aryl Halides. Chem. Sci. 2017, 8, 4437-4442. (c) Markovic, T.; Rocke, B. N.; Blakemore, D. C.; Mascitti, V.; Willis, M. C. Catalyst Selection Facilitates the Use of Heterocyclic Sulfinates as General Nucleophilic Coupling Partners in Palladium-Catalyzed Coupling Reactions. Org. Lett. 2017, 19, 6033-6035. (d) Markovic, T.; Murray, P. R. D.; Rocke, B. N.; Shavnya, A.; Blakemore, D. C.; Willis, M. C. Heterocyclic Allylsulfones as Latent Heteroaryl Nucleophiles in Palladium-Catalyzed Cross-Coupling Reactions. J. Am. Chem. Soc. 2018, 140, 15916-15923.

(17) Smith, J. M.; Dixon, J. A.; deGruyter, J. N.; Baran, P. S. Alkyl Sulfinates: Radical Precursors Enabling Drug Discovery. J. Med. Chem. 2019, 62, 2256-2264.

(18) (a) Johnson, M. W.; Bagley, S. W.; Mankad, N. P.; Bergman, R. G.; Mascitti, V.; Toste, F. D. Application of Fundamental Organometallic Chemistry to the Development of a Gold-Catalyzed Synthesis of Sulfinate Derivatives. Angew. Chem., Int. Ed. 2014, 53, 4404-4407. (b) Zhu, H.; Shen, Y.; Deng, Q.; Chen, J.; Tu, T. Acenaphthoimidazolylidene Gold Complex-Catalyzed Alkylsulfonylation of Boronic Acids by Potassium Metabisulfite and Alkyl Halides: A Direct and Robust Protocol To Access Sulfones. ACS Catal. 2017, 7, 4655-4659. (c) Zhu, H.; Shen, Y.; Wen, D.; Le, Z. G.; Tu, T. Selective Synthesis of ortho-Substituted Diarylsulfones by Using NHC-Au Catalysts under Mild Conditions. Org. Lett. 2019, 21, 974-979.

(19) (a) Shavnya, A.; Hesp, K. D.; Mascitti, V.; Smith, A. C. Palladium-Catalyzed Synthesis of (Hetero)Aryl Alkyl Sulfones from (Hetero)Aryl Boronic Acids, Unactivated Alkyl Halides, and Potassium Metabisulfite. Angew. Chem., Int. Ed. 2015, 54, 1357113575. (b) Zhu, H.; Shen, Y.; Deng, Q.; Chen, J.; Tu, T. Pd(NHC)Catalyzed Alkylsulfonylation of Boronic Acids: A General and Efficient Approach for Sulfone Synthesis. Chem. Commun. 2017, 53, 12473-12476.

(20) Ye, S.; Wu, J. A Palladium-Catalyzed Three-Component Coupling of Arylboronic Acids, Sulfur Dioxide and Hydrazines. Chem. Commun. 2012, 48, 7753-7755.

(21) (a) Su, B.; Cao, Z. C.; Shi, Z. J. Exploration of Earth-Abundant Transition Metals ( $\mathrm{Fe}, \mathrm{Co}$, and $\mathrm{Ni}$ ) as Catalysts in Unreactive Chemical Bond Activations. Acc. Chem. Res. 2015, 48, 886-896. (b) Maes, J.; Mitchell, E. A.; Maes, B. U. W. Base Metals in Catalysis: From Zero to Hero. In Green and Sustainable Medicinal Chemistry: Methods, Tools and Strategies for the 21st Century Pharmaceutical Industry; Summerton, L., Sneddon, H. F, Jones, L. C., Clark, J. H.,
Eds.; The Royal Society of Chemistry: Cambridge, 2016; pp 192202.

(22) (a) Rosen, B. M.; Quasdorf, K. W.; Wilson, D. A.; Zhang, N.; Resmerita, A.-M.; Garg, N. K.; Percec, V. Nickel-Catalyzed CrossCouplings Involving Carbon-Oxygen Bonds. Chem. Rev. 2011, 111, 1346-1416. (b) Tobisu, M.; Chatani, N. Cross-Couplings Using Aryl Ethers via $\mathrm{C}-\mathrm{O}$ Bond Activation Enabled by Nickel Catalysts. Acc. Chem. Res. 2015, 48, 1717-1726. (c) Tasker, S. Z.; Standley, E. A.; Jamison, T. F. Recent Advances in Homogeneous Nickel Catalysis. Nature 2014, 509, 299-309. (d) Ananikov, V. P. Nickel: The "Spirited Horse" of Transition Metal Catalysis. ACS Catal. 2015, 5, 1964-1971. (e) Hazari, N.; Melvin, P. R.; Beromi, M. M. WellDefined Nickel and Palladium Precatalysts for Cross-Coupling. Nat. Rev. Chem. 2017, 1, 0025. (f) Börjesson, M.; Moragas, T.; Gallego, D.; Martin, R. Metal-Catalyzed Carboxylation of Organic (Pseudo)halides with $\mathrm{CO}_{2}$. ACS Catal. 2016, 6, 6739-6749.

(23) Twilton, J.; Le, C.; Zhang, P.; Shaw, M. H.; Evans, R. W.; MacMillan, D. W. C. The Merger of Transition Metal and Photocatalysis. Nat. Rev. Chem. 2017, 1, 0052.

(24) Le Duc, G.; Bernoud, E.; Prestat, G.; Cacchi, S.; Fabrizi, G.; Iazzetti, A.; Madec, D.; Poli, G. Palladium-Catalyzed Aromatic Sulfonylation: A New Catalytic Domino Process Exploiting in situ Generated Sulfinate Anions. Synlett 2011, 2011, 2943-2946.

(25) Graham, S. L.; Scholz, T. H. The Reaction of Sulfinic Acid Salts with Hydroxylamine-O-sulfonic Acid. A Useful Synthesis of Primary Sulfonamides. Synthesis 1986, 1986, 1031-1032.

(26) Dong, J.; Krasnova, L.; Finn, M. G.; Sharpless, K. B. Sulfur(VI) Fluoride Exchange (SuFEx): Another Good Reaction for Click Chemistry. Angew. Chem., Int. Ed. 2014, 53, 9430-9448.

(27) (a) Caddick, S.; Wilden, J. D.; Bush, H. D.; Wadman, S. N.; Judd, D. B. A New Route to Sulfonamides via Intermolecular Radical Addition to Pentafluorophenyl Vinylsulfonate and Subsequent Aminolysis. Org. Lett. 2002, 4, 2549-2551. (b) Caddick, S.; Wilden, J. D.; Bush, H. D.; Judd, D. B. Synthesis of Functionalised Sulfonamides via Microwave Assisted Displacement of PFPSulfonates with Amines. QSAR Comb. Sci. 2004, 23, 902-905. (c) Caddick, S.; Wilden, J. D.; Judd, D. B. Observations on the Reactivity of Pentafluorophenyl Sulfonate Esters. Chem. Commun. 2005, 2727-2728. 